\title{
Male-female estimates of opposite-sex first impressions concerning females' clothing styles
}

\author{
DELWIN D. CAHOON and ED M. EDMONDS \\ Augusta College, Augusta, Georgia
}

\begin{abstract}
Men and women college students recorded their impressions of a model dressed either conservatively or in clothing judged to be sexually provocative, and also attempted to estimate the impressions of a typical member of the opposite sex. The results indicated a generally negative bias toward women wearing provocative clothing. The most striking finding was that females greatly overestimated the extent of male rape motivation.
\end{abstract}

There is ample evidence that men and women tend to differ with respect to attitudes concerning love and sex. For example, Hendrick and Hendrick (1986), found that men were more likely to accept statements concerning ludus (i.e., concerning game-playing love), while women were more inclined to personally endorse statements in the areas of storge (friendship love), pragma (practical love), and mania (possessive, dependent love). No differences were found between the sexes regarding eros (passionate love) and agape (all-giving, selfless love). Abbey (1982) reports that males tend to misinterpret the social behavior of females as indicating sexual interest even when no such message is intended. In this study, a male and female participated in a 5-min conversation while observed by a concealed male and female. The results indicated that college-age male actors and observers rated the female actor as more promiscuous and seductive than she was rated by female actors and observers. Males also reported greater sexual attraction to the opposite-sex partner than did females, and were more likely to perceive sexual interest on the part of other males. The present investigation was designed to assess the accuracy with which men and women can estimate opinions of the opposite sex with respect to sexual-social issues as a function of variation in female clothing style.

\section{METHOD}

Forty-four men and 81 women in introductory psychology classes were shown one of two slides. One slide featured a college-age caucasian female wearing slacks and a blouse that were judged to be somewhat conservative. The other slide featured the same model in a revealing dress that might be considered sexy or provocative. A previous study (Edmonds \& Cahoon, 1986) had confirmed the assessments of the two clothing styles as sexy and nonsexy and had revealed no differences in ratings of the clothing styles with the model's face obscured or with the photograph unaltered. The slides were therefore cropped at neck level in order to minimize cues related to facial expression. The same model was shown in both slides, and the two poses were similar. The subjects were asked to complete a questionnaire indicating their impressions of the female and also to estimate the opinions of a typical member of the opposite sex.

Requests for reprints may be sent to Delwin D. Cahoon, Department of Psychology, Augusta College, Augusta, Georgia 30910.

\section{RESULTS AND DISCUSSION}

The results were analyzed by means of an analysis of variance classified by sex of rater, style of garment, and own opinion versus estimated opposite-sex opinion. A summary of this analysis follows:

1. "How attractive is this woman?" The model was rated as more attractive by the males than by the females $[F(1,121)=11.51, p<.001]$. Both males and females rated the model wearing the sexy garment to be more attractive than the model wearing conservative clothing $[F(1,121)=7.99, p<.005]$. A significant interaction was found among sex of rater, style of clothing, and accuracy in estimating the opinion of the opposite sex $[F(1,121)=7.47, p=.007]$. The females predicted that the males would rate the model as more attractive than she would be rated by the females. The males estimated that the females would judge the model wearing sexy clothes to be less attractive than she would be evaluated by the males.

2. "To what extent would this woman impress men as being sexually exciting?" Both males and females judged sexy clothes as more sexually exciting to men than nonsexy clothes $[F(1,121)=25.95, p<.001]$. An interaction was also found between sex of rater and estimated opinion of the opposite $\operatorname{sex}[F(1,121)=37.562$, $p<.001]$. The males predicted that the females would rate the model as less sexually exciting (to males) than she would be evaluated by the males. Females predicted that males would rate the model as more sexually exciting than she was rated by the females.

3. "At what age would this female most likely first engage in sexual intercourse?" Both male and female raters believed that the model wearing sexy clothes would engage in sexual intercourse at an earlier age $(\bar{X}=14$ years) than the model wearing nonsexy clothes $(\bar{X}=17$ years) $[F(1,121)=26.65, p<.001]$. Both males and females believed that the opposite sex would predict an earlier age for sexual activity than their own estimates $[F(1,121)=20.62, p<.001]$.

4. "To what extent is this woman sexually active?" All raters perceived the model wearing sexy clothing as 
more active sexually than the model wearing nonsexy clothing $[F(1,121)=27.453, p<.001]$. An interaction was found between sex of rater and estimated opinion of the opposite sex $[F(1,121)=8.785, p<.003]$. Males predicted that their ratings and the ratings of the females would be the same. Females believed that the males would rate the model as being more sexually active than she would be rated by females.

5. "To what extent is this woman a flirt or a sexual tease?" All raters agreed that the model wearing sexy clothing was more of a flirt and a tease than the model wearing nonsexy clothing $[F(1,121)=27.055$, $p<.001]$. Males and females also felt that they would rate the model as being less of a flirt or tease than she would be rated by the opposite sex $[F(1,121)=13.152$, $p<.001]$.

6. "To what extent would this woman use sex appeal to her advantage on the job or in school?'" Both males and females believed that the model wearing sexy clothes would use sex appeal to a greater extent than the model wearing nonsexy clothes $[F(1,121)=22.027, p<.001]$. Both male and female raters believed that they would rate the model as using sex appeal to a lesser extent than she would be rated by the opposite $\operatorname{sex}[F(1,121)=9.49, p<.002]$.

7. "If this woman were married, how likely is it that she would remain faithful to her hustand?" Male and female raters agreed that the model in sexy clothes was less likely to remain faithful $[F(1,121)=20.65, p<.001]$. Raters also agreed that they would estimate the model as remaining faithful to a greater extent than would the opposite $\operatorname{sex}[F(1,121)=20.379, p<.001]$.

8. "How likely is this woman to be mugged compared with other females of the same age?" Both males and females saw the model wearing sexy clothes as more likely to be mugged than the model wearing nonsexy clothes $[F(1,121)=9.730, p<.002]$.

9. "How likely is this woman to be raped compared with other females of the same age?" Both groups of subjects agreed that the model wearing sexy clothes was more likely to be raped $[F(1,121)=4.372, p<.05]$. An interaction was also found between style of clothing and estimated opinion of the opposite sex $[F(1,121)=7.234$, $p<.008$ ]. Both males and females believed that they had rated the model wearing nonsexy clothes as less likely to be raped than she would be rated by the opposite sex. No such difference was found with respect to the sexy clothes condition.

10. "If a man could mug this woman without fear of being caught, how likely is it that he would do so?" No significant differences were found between any of the conditions.

11. "If a man could rape this woman without fear of being caught, how likely is it that he would do so?" Both men and women believed that a man would more likely rape the model wearing sexy clothes $[F(1,121)=5.38$, $p<.02]$.

The results were consistent with studies describing a generally negative bias toward women wearing provocative clothing (Edmonds \& Cahoon, 1986). While the model in the sexy-clothing condition was judged to be more attractive and sexually appealing to men, she was viewed more negatively with respect to age of first intercourse, sexual teasing, extent of sexual activity, using sex for personal gain, and faithfulness in marriage. The sexy model was also viewed as more likely to be raped or robbed, a finding previously reported by Edmonds \& Cahoon (1986). Male and female raters tended to agree in their judgments although men rated the model positively on more items than she was rated by the female subjects.

Differences were found between men and women with respect to accuracy in predicting the opinions of the opposite sex, with women making significantly more and larger errors $[F(1,60)=29.97, p<.001]$. In general, women assumed that men would view the model more negatively than was actually the case. Men were also asked to indicate the likelihood that they would rape the model if they could do so with impunity. While $7.6 \%$ of the men endorsed the possibility of raping the conservatively dressed model, $38.8 \%$ admitted to the possibility of raping the model dressed in sexually provocative clothing. In an earlier study Malamuth, Haber and Feshback (1980) asked undergraduate males to assess the likelihood that they would commit rape if they could be assured that they would not be caught. Fifty-one percent of the subjects admitted to some possibility of rape under those circumstances. In a related study Tieger (1981) found that $37 \%$ of junior college males agreed that they would rape if they would not have to suffer the consequences. The present results would seem to be consistent with those studies, allowing for differences in research procedures.

Most striking is the fact that females greatly overestimated the male percentages concerning the likelihood of rape. While, as noted above, $7.6 \%$ of the male subjects admitted to the possibility of raping the conservatively dressed model, women predicted that $36.3 \%$ of the men would respond positively. Corresponding percentages for the sexually provocative model were $38.8 \%$ for men and $61.6 \%$ for women. Apparently, in addition to a tendency for men to view the world in sexual terms (Abbey, 1982) there is a corresponding tendency for women to misjudge male sexual attitudes, especially men's motivation to rape.

\section{REFERENCES}

ABBey, A. (1982). Sex differences in attribution for friendly behavior: Do males misperceive females' friendliness? Journal of Personality \& Social Psychology, 42, 830-838.

EDMONDS, E. M., \& CAHOON, D. D. (1986). Attitudes concerning crimes related to clothing worn by female victims. Bulletin of the Psychonomic Society, 24, 444-446.

Hendrick, C., \& Hendrick, S. (1986). A theory and method of love. Journal of Personality \& Social Psychology, 50(2), 392-402.

Malamuth, N. M., Haber, S., \& Feshback, S. (1980). Testing hypotheses concerning rape: Exposure to sexual violence, sex differences, and the "normality" of rapists. Journal of Research in Personality, 14, 121-137.

TIEgER, T. (1981). Self-rated likelihood of raping and the social perception of rape. Journal of Research in Personality, 15, 147-158. 